\title{
All-cause mortality and risk factors in a cohort of retired military male veterans, Xi'an, China: an I8-year follow up study Xiao Y Sai ${ }^{1}$, Yao He ${ }^{2}$, Ke Men ${ }^{1}$, Bo Wang1, Jiu Y Huang ${ }^{1}$, Qiu L Shi' ${ }^{1}$, Lei Zhang1, Liang S Li¹, Bernard CK Choi ${ }^{3,4}$ and Yong P Yan*1
}

\begin{abstract}
Address: ${ }^{1}$ Department of Epidemiology, College of Military Services and Statistics, Fourth Military Medical University, Xi'an, China, ${ }^{2}$ Department of Epidemiology, Institute of Geriatrics, Chinese PLA General Hospital, Beijing, China, ${ }^{3}$ Department of Public Health Sciences, University of Toronto, Toronto, Canada and ${ }^{4}$ Department of Epidemiology and Community Medicine, University of Ottawa, Ottawa, Canada

Email: Xiao Y Sai - saixiaoyong@163.com; Yao He - yhe301@x263.net; Ke Men - gncbmk@fmmu.edu.cn; Bo Wang - wangbo@fmmu.edu.cn; Jiu Y Huang - junliu@fmmu.edu.cn; Qiu L Shi - qlingshi@fmmu.edu.cn; Lei Zhang - shaoyulei@yahoo.com;

Liang S Li - liliangshou@fmmu.edu.cn; Bernard CK Choi - Bernard.Choi@utoronto.ca; Yong P Yan* - yanyping@fmmu.edu.cn

* Corresponding author
\end{abstract}

Published: 12 October 2007

BMC Public Health 2007, 7:290 doi:10.1 186/1471-2458-7-290

This article is available from: http://www.biomedcentral.com/I47I-2458/7/290

(C) 2007 Sai et al; licensee BioMed Central Ltd.

This is an Open Access article distributed under the terms of the Creative Commons Attribution License (http://creativecommons.org/licenses/by/2.0), which permits unrestricted use, distribution, and reproduction in any medium, provided the original work is properly cited.

\begin{abstract}
Background: Risk factors of all-cause mortality have not been reported in Chinese retired military veterans. The objective of the study was to examine the risk factors and proportional mortality in a Chinese retired military male cohort.

Methods: A total of 1268 retired military men aged 55 or older were examined physically and interviewed using a standard questionnaire in 1987. The cohort was followed up every two years and the study censored date was June30, 2005 with a follow-up of up to 18 years. Death certificates were obtained from hospitals and verified by two senior doctors. Data were entered (double entry) by Foxbase, and analysis was carried out by SAS for Windows 8.2. Multivariate Cox proportional hazard regression model was used to compute hazard ratio (HR) and $95 \%$ confidence interval $(\mathrm{Cl})$.

Results: The total person-years of follow-up was 18766.28. Of the initial cohort of 1268 men, 49I had died, 748 were alive and 29 were lost to follow up. Adjusted mortality (adjusted for age, blood pressure, body mass index, cholesterol, triglycerides, alcohol, exercise, and existing disease) was 2,616 per 100,000 person years. The proportional mortality of cancer, vascular disease and Chronic Obstructive Pulmonary Disease (COPD) were $39.71 \%, 28.10 \%$ and $16.90 \%$ respectively. Multivariate analysis showed that age, cigarettes per day, systolic blood pressure, triglyceride, family history of diseases (hypertension, stroke and cancer), existing diseases (stroke, diabetes and cancer), body mass index, and age of starting smoking were associated with all-cause mortality, HR $(95 \% \mathrm{Cl})$ wasl.083(I.062-I.104), I.026(I.0I3-I.039), I.009(I.003-1.015), I.002(1.00I-1.003), I.330(I.005-1.759), I.330(I.005-I.759), I.444(1.103-1.890), $2.237(I .244-4.022), \quad I .462(I .042-2.05 I), 2.079(I .05 I-4.1 I 5), 0.963(0.93 I-0.996)$ and $0.988(0.978-0.999)$ respectively. Compared with never-smokers, current smokers had increased risks of total mortality [HR I.369(I.083-I.73I)], CHD [HR I.805 (I.022-3.188)], and lung cancer [HR 2.939 (I.3II-6.585)].
\end{abstract}

Conclusion: The three leading causes of diseases were cancer, CHD and stroke, and COPD. Aging, cigarette smoking, high systolic blood pressure, high triglyceride, family history of cancer, hypertension and stroke, existing cases recovering from stroke, diabetes and cancer, underweight, younger age of smoking were risk factors for all-cause mortality. Quitting cigarette smoking, maintaining normal blood pressure, triglyceride and weight are effect control strategies to prevent premature mortality in this military cohort. 


\section{Background}

Chronic non-communicable diseases were estimated to account for 35 million or $60 \%$ of all deaths globally in 2005[1]. It is vital to identify risk factors and control the rapidly growing epidemic of chronic diseases. In China, risk factors for all-cause mortality have not been reported, especially in retired military veterans. Two questions remain to be resolved: one was "which diseases had a huge burden among retired military veterans?" the other was "how to prevent them?" To identify the risk factors for all-cause mortality and to improve the health service for retired military veterans, a Chinese retired military male cohort was set up in 1987 and followed up to June 30, 2005.

\section{Methods \\ Study Population}

From February to June in 1987, a cross-sectional survey was carried out in 22 military retirement centers in Xi'an, China. As there were few women, only men (1268 or $98 \%$ of all eligible) were included in the survey.

\section{Baseline Measurements}

Each participant was interviewed and completed a standardized questionnaire that included a range of demographic factors, aspects of medical history, family history of diseases, and lifestyle. The questionnaire were designed and defined using the WHO MONICA criteria [2]. The physical examinations and interview were carried out by trained nurses and physicians.

The average age of entering the cohort was $62.95 \pm 5.18$ years. Existing diseases included coronary heart disease (CHD), stroke, hypertension, diabetes, Chronic Obstructive Pulmonary Disease(COPD)and cancer, which were diagnosed by local hospitals. Height was measured in meters (without shoes), and weight in kilogram (with heavy clothing removed and $1 \mathrm{~kg}$ deducted for remaining garments). Body mass index (BMI) was calculated as weight $(\mathrm{kg}) /$ height $(\mathrm{m})^{2}$. BMI was divided into four levels: $<18.5,18.5-23.9,24-27.9$, and $\geq 28$. Total cholesterol and triglycerides were measured using the standard enzymatic method and Hontzschs test (acetylacetone), respectively [3]. Triglycerides was divided into four levels: $<90$ $\mathrm{mg} / \mathrm{dl}, 90-122 \mathrm{mg} / \mathrm{dl}, 123-151 \mathrm{mg} / \mathrm{dl}$, and $\geq 152 \mathrm{mg} / \mathrm{dl}$.

Two blood pressure recordings were obtained from the right arm of patients in a sitting position after 30 minutes of rest; measurements were taken in 5-minute intervals, and mean values were calculated. Systolic blood pressure was divided into four levels: $<120 \mathrm{mmHg}, 120-129$ $\mathrm{mmHg}, 130-139 \mathrm{mmHg}$, and $\geq 140 \mathrm{mmHg}$. According to the standard of World Health Organization (WHO) in 1978, borderline hypertensive was defined as one whose systolic blood pressure was between 141 159 mmHg and diastolic pressure was between 91 95 mmHg; Hypertension was defined as one whose systolic blood pressure was higher than $159 \mathrm{mmHg}$ and diastolic pressure was higher than $95 \mathrm{mmHg}$.

The categories of smoking were never smoking, former smoking, and current smoking. An ever-smoker was defined as one who had smoked at least one cigarette daily for one year or more. Current smokers were eversmokers who were smoking at baseline, and former smokers were those who had stopped for at least two years. Smoking index $=$ cigarettes per day $\times$ duration of smoking. Smoking index was divided into four levels: <350, 350-569, 570-749, and $\geq 750$.

Current drinking was defined as average alcohol consumption of more than $10 \mathrm{~g}$ of absolute alcohol per day for more than 1 year in the past 5 years.

\section{Follow-up}

The cohort was a fixed cohort which was followed up every two years for all cause death. Death certificates were obtained from hospitals and verified by two senior doctors. The causes were coded according to the International Classification of Diseases, Ninth Edition.

\section{Statistical Analysis}

Data were entered (double entry), and analysis was carried out by SAS for Windows 8.2. Multivariate Cox proportional hazard regression model was used to compute HR and 95\% CI. Potential confounders adjusted for included age, systolic blood pressure, BMI, total cholesterol, triglycerides, regular alcohol consumption (yes or no), regular exercise(yes or no), family history of diseases(yes or no) and existing disease(yes or no, or years of disease, as appropriate).

\section{Ethical considerations}

The committee for medical ethics of the Chinese PLA General Hospital approved the study. Each participant signed an informed consent form before completing the questionnaire.

\section{Results}

Up to June 30, 2005, a total of 748 individuals were alive, 29 were transferred away with unknown vital status (the last date of known survival, which was end of Jan 1997, was considered as the censored date), and 491 had died. Adjusted mortality was 2616 per 100,000 person years. Death certificates were available for all the deaths since they all occurred in hospitals. The five leading causes of death were malignant tumor (39.71\%), COPD (16.90\%), CHD (16.90\%), stroke (11.20\%) and diabetes (4.68\%). Adjusted mortality rates were 1039, 442, 421, 293 and 123 per 100,000 person years respectively. 
Table 1 shows characteristics of never, ever smokers at baseline in 1987. Age, BMI, diastolic, systolic, total cholesterol, triglycerides, existing disease including stroke, hypertension, diabetes, COPD and cancers between two groups had no significant differences ( $P>0.05) .64 .89 \%$ and $59.20 \%$ of ever smokers exercised and drank regularly, which were higher than never smoker $(\mathrm{P}<0.05)$. Prevalence of CHD in ever smokers was higher than never smokers $(29.89 \%$ vs. $23.71 \%, \mathrm{P}<0.05)$.

Table 2 shows adjusted HR of major causes of death by smoking status at baseline. Compared with never-smokers, current smokers had increased risks of total mortality [HR 1.369(1.083-1.731)], CHD [HR 1.805 (1.022-3.188)], and lung cancer [HR 2.939 $(1.311-6.585)]$.

Table 3 shows that age, cigarettes per day, duration of smoking, systolic blood pressure, triglycerides, negative affairs, exercise, family history of diseases including hypertension, stroke and cancer and existing diseases (including CHD, stroke, hypertension, cerebral arteriosclerosis, diabetes, COPD and cancer) were associated with all cause mortality $(\mathrm{P}<0.05)$. After adjusted for all other factors under study, age, cigarettes per day, systolic blood pressure, triglycerides, BMI, age of starting smoking, family history of diseases including cancer, hypertension and stroke, and existing diseases including stroke, diabetes and cancer were found to be associated with all cause mortality $(\mathrm{P}<0.05)$.

Table I: Characteristics of never, ever smokers at baseline in 1987

\begin{tabular}{|c|c|c|}
\hline & $\begin{array}{l}\text { Never } \\
\text { smoker } \\
(n=388)\end{array}$ & $\begin{array}{l}\text { Ever smoker } \\
(\mathrm{n}=880)\end{array}$ \\
\hline Age, mean(SD), years & $62.52(5.20)$ & $63.13(5.16)$ \\
\hline $\mathrm{BMI}, \operatorname{mean}(\mathrm{SD})$ & $24.36(2.95)$ & $24.31(3.09)$ \\
\hline \multicolumn{3}{|l|}{$\mathrm{BP}, \operatorname{mean}(\mathrm{SD}), \mathrm{mmHg}$} \\
\hline Diastolic & $80.60(11.41)$ & $79.72(10.83)$ \\
\hline Systolic & $129.55(18.86)$ & $129.01(18.12)$ \\
\hline Total cholesterol, mg/dl, mean(SD) & 193.92(43.84) & $196.69(43.04)$ \\
\hline Triglycerides, mg/dl, mean(SD) & 133.62(72.95) & 133.02(65.20) \\
\hline $\begin{array}{l}\text { Duration of follow up, years, } \\
\text { mean(SD) }\end{array}$ & $15.23(5.30)$ & $|4.6|(5.50)$ \\
\hline Regular exercises, Yes, n (\%)* & $22 I(56.96)$ & $57 \mid(64.89)$ \\
\hline Regular alcohol, Yes, n (\%)* & $129(33.25)$ & $521(59.20)$ \\
\hline \multicolumn{3}{|l|}{ Existing disease(Yes) } \\
\hline CHD, n (\%)* & $92(23.7 I)$ & $263(29.89)$ \\
\hline Stroke, n (\%) & $6(1.55)$ & $14(\mid .59)$ \\
\hline Hypertension, n (\%) & $87(22.42)$ & $209(23.75)$ \\
\hline Diabetes, n (\%) & $20(5.15)$ & $58(6.59)$ \\
\hline COPD, n (\%)* & $49(12.63)$ & $246(27.95)$ \\
\hline Cancers, n (\%) & $4(1.03)$ & $15(1.70)$ \\
\hline
\end{tabular}

* Chi-square, two degrees of freedom: $p<0.05$
Table 4 shows that HR and 95\% CI of continuous variable when divided into polytomous categories. Age, smoking index, age of starting smoking, cigarettes per day, systolic blood pressure and triglycerides had significant difference in linear trends $(P<0.05)$. Compared with current smokers, HR of former smokers decreased to $75.88 \%$, following computation methods described in a previous paper [3].

\section{Discussion}

As estimated by WHO [1], among the 58 million deaths in the world in 2005, noncommunicable diseases accounted for 35 million, which was double the number of deaths from all communicable diseases (including HIV/AIDS, tuberculosis and malaria), maternal and perinatal conditions, and nutritional deficiencies combined. Sixteen million of the 35 million deaths occurred in people aged less than 70 years. In 2005, 53\% of all deaths were among people aged 60 years and older. By 2030, this respective proportion is expected to be $62 \%$. With aging, chronic disease will become more serious. If no action is taken, some 388 million deaths will occur in the following 10 years globally and 80 million deaths will occur in China. Just cardiac disease, stroke and diabetes will cause an economic loss of 550 billion dollars in China.

Different society, culture and economy may lead to different proportional mortality rate and disease burden in the world. The Chinese Ministry of Health reported that in China the three leading causes of death are cancers $(22.94 \%)$, cerebrovascular disease $(21.23 \%)$, heart disease $(17.89 \%)$ in cities; and respiratory system Diseases $(23.45 \%)$, cerebrovascular disease $(21.27 \%)$ and cancers $(20.29 \%)$ in the countryside respectively [4]. Globally, WHO's three leading death diseases are angiocardiopathy $(30 \%)$, cancers $(13 \%)$ and chronic respiratory disease $(7 \%)$.

The objective of our study was to identify proportional mortality and risk factors of a retired military cohort. This was vital to improve the health service for Chinese retired military veterans. The three leading causes of death were found to be cancers $(39.71 \%)$, angiocardiopathy and cerebrovascular disease $(27.29 \%)$ and COPD $(16.90 \%)$ in our cohort. The order was similar to order of death burdens in cities reported by the Chinese Ministry of Health in 2005.

Many other published cohort studies focused on a single cause of death or disease, and/or a single risk factor. For example, Eaker used data from Framingham Offspring Study and tried to identify the relationship between job stress and CHD [5]. There were few studies on the risk factors for all-cause death. Furthermore, would the risk factors observed in an elderly cohort be same to those in the general population? In China, many studies on risk fac- 


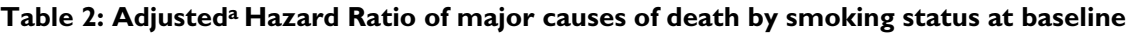

\begin{tabular}{|c|c|c|c|c|c|c|c|c|c|}
\hline & \multirow{2}{*}{$\begin{array}{c}\begin{array}{c}\text { Never- } \\
\text { smoker } \\
(\mathrm{N}=388)\end{array} \\
\text { No. of death }\end{array}$} & \multicolumn{4}{|c|}{ Former smoker $(\mathrm{N}=46 \mathrm{I})$} & \multicolumn{4}{|c|}{ Current smoker $(\mathrm{N}=419)$} \\
\hline & & No. of death & HR & $95 \% \mathrm{Cl}$ & $P$ & No. of death & $H R$ & $95 \% \mathrm{Cl}$ & $P$ \\
\hline All causes & 126 & 193 & 1.089 & $0.865-1.372$ & 0.467 & 172 & 1.369 & $|.083-1.73|$ & 0.009 \\
\hline $\mathrm{CHD}$ & 21 & 25 & 0.681 & $0.376-1.233$ & 0.205 & 33 & 1.805 & $1.022-3.188$ & 0.042 \\
\hline Stroke & 17 & 20 & 0.863 & $0.447-1.666$ & 0.660 & 18 & 1.087 & $0.552-2.141$ & 0.808 \\
\hline Lung cancer & 8 & 27 & 2.622 & $1.165-5.900$ & 0.020 & 25 & 2.939 & $1.311-6.585$ & 0.009 \\
\hline COPD & 14 & 42 & 1.856 & $0.993-3.470$ & 0.053 & 27 & 1.517 & $0.784-2.936$ & 0.216 \\
\hline
\end{tabular}

a: Adjusted for age, systolic blood pressure, body mass index, total cholesterol, triglycerides, regular alcohol consumption, exercise, as well as existing disease at baseline.

tors were case-control studies. These subjects were mainly from outpatients, which could not represent the general population. In order to identify risk factors of all-cause mortality, we followed up the cohort from 1987 to 2005.

Up to now, the relationship between BMI and death has been a hot topic in the world and still has many arguments $[6,7]$. WHO divides BMI into four groups: underweight $(\mathrm{BMI}<18.5)$, normal $(18.5<\quad \mathrm{BMI}<24.9)$, overweight $(25<$ BMI $<29.9)$ and obesity (BMI $>30)$. Cooperative Meta-analysis Group of China Obesity Task Force [8] proposed separate criteria for Chinese adults by analyzing the data of 239972 Chinese: underweight
$(\mathrm{BMI}<18.5), \quad$ normal $\quad(18.5<\mathrm{BMI}<23.9), \quad$ overweight $(24<\mathrm{BMI}<27.9)$ and obesity (BMI>28). When our cohort was divided into four groups according to the Chinese criteria, compared with normal group, underweight group had a significant risk(HR 2.03), although HR of overweight group and obesity group was not significant $(\mathrm{P}>$ 0.05).

WHO reported that underweight was a risk factor of death in all age groups. Underweight was estimated to cause 3.7 million deaths in 2000. Overweight and obesity led to adverse metabolic effects on blood pressure, cholesterol, triglycerides and insulin resistance. Risks of CHD,

Table 3: Hazard Ratios and $95 \% \mathrm{Cl}$ for risk factor for all cause mortality

\begin{tabular}{|c|c|c|c|c|c|}
\hline Risk Factor & Crude HR' & $95 \% \mathrm{Cl}$ & Adjusted $\mathrm{HR}^{2}$ & $95 \% \mathrm{Cl}$ & $P$ \\
\hline age (year) & 1.091 & $1.074-1.109$ & 1.083 & $1.062-1.104$ & $<0.001$ \\
\hline systolic blood pressure $(\mathrm{mmHg})$ & 1.012 & $1.007-1.016$ & 1.009 & $1.003-1.015$ & 0.003 \\
\hline triglycerides $(\mathrm{mg} / \mathrm{dl})$ & 1.002 & $1.001-1.003$ & 1.002 & $1.001-1.003$ & 0.009 \\
\hline \multicolumn{6}{|l|}{ Smoking status } \\
\hline cigarettes per day (number) & 1.023 & $1.015-1.032$ & 1.026 & $1.013-1.039$ & $<0.001$ \\
\hline duration of smoking (year) & 1.012 & $1.006-1.017$ & 1.005 & $0.997-1.013$ & 0.218 \\
\hline age of starting smoking (year) & 1.003 & $0.996-1.011$ & 0.988 & $0.978-0.999$ & 0.028 \\
\hline exercise (yes/no) & 0.920 & $0.888-0.953$ & 0.922 & $0.739-1.152$ & 0.476 \\
\hline $\operatorname{BMI}\left(\mathrm{kg} / \mathrm{m}^{2}\right)$ & 0.986 & $0.957-1.015$ & 0.963 & $0.931-0.996$ & 0.026 \\
\hline negative affairs (yes/no) & $1.47 \mid$ & $1.172-1.845$ & 1.173 & $0.927-1.483$ & 0.183 \\
\hline \multicolumn{6}{|l|}{ family history (yes/no) } \\
\hline hypertension & 1.455 & $1.122-1.886$ & 1.330 & $1.005-1.759$ & 0.046 \\
\hline stroke & 1.455 & $1.122-1.886$ & 1.330 & $1.005-1.759$ & 0.046 \\
\hline cancer & 1.282 & $1.000-1.644$ & 1.444 & $1.103-1.890$ & 0.007 \\
\hline \multicolumn{6}{|l|}{ Existing disease (yes/no) } \\
\hline cancer & 3.596 & $2.150-6.015$ & 2.079 & $1.05 I-4.115$ & 0.036 \\
\hline stroke & 2.235 & $1.288-3.878$ & 2.237 & $1.244-4.022$ & 0.007 \\
\hline diabetes & 1.909 & $1.405-2.595$ & 1.462 & $|.042-2.05|$ & 0.028 \\
\hline $\mathrm{CHD}$ & 1.425 & $1.182-1.719$ & 0.941 & $0.750-1.179$ & 0.596 \\
\hline hypertension & 1.406 & $1.155-1.712$ & 1.025 & $0.790-1.329$ & 0.853 \\
\hline COPD & 1.409 & $1.156-1.717$ & 1.087 & $0.87 \mid-1.357$ & 0.460 \\
\hline cerebral arteriosclerosis & 1.391 & $1.093-1.769$ & 1.126 & $0.864-1.467$ & 0.380 \\
\hline
\end{tabular}

I: crude hazard ratio; 2: adjusted hazard ratio (adjusted for age, systolic blood pressure, triglycerides, cigarettes per day, duration of smoking, age of starting smoking, exercise, BMI, negative affairs, family history of diseases including hypertension, stroke and cancer, and existing all kinds of diseases at baseline) 
Table 4: Hazard Ratio and $95 \% \mathrm{Cl}$ of continuous variables into 4 categories for all cause mortality

\begin{tabular}{|c|c|c|c|c|c|}
\hline & Deaths & HR & $95 \% \mathrm{Cl}$ & $P$ & $P$ for trend \\
\hline age (year) & 491 & & & & $<0.001$ \\
\hline$\leq 59$ & 75 & 1.000 & & & \\
\hline $59-62$ & 102 & 1.453 & $1.077-1.960$ & 0.015 & \\
\hline $63-66$ & 130 & 2.131 & $1.077-2.835$ & $<0.001$ & \\
\hline$\geq 66$ & 184 & 3.405 & $2.599-4.462$ & $<0.001$ & \\
\hline smoking status* & 491 & & & & \\
\hline non smokers & 126 & 1.000 & & & \\
\hline former smokers & 193 & 1.089 & $0.865-1.372$ & 0.467 & \\
\hline current smokers & 172 & 1.369 & $|.083-1.73|$ & 0.009 & \\
\hline smoking index & 172 & & & & $<0.001$ \\
\hline$<350$ & 34 & 1.000 & & & \\
\hline $350-569$ & 29 & 1.163 & $0.901-1.501$ & 0.2457 & \\
\hline $570-749$ & 48 & 1.531 & $1.188-1.974$ & 0.001 & \\
\hline$\geq 750$ & 61 & 2.069 & $1.642-2.606$ & $<0.001$ & \\
\hline age of starting smoking (year) & 365 & & & & 0.038 \\
\hline$<19$ & 101 & 1.000 & & & \\
\hline $19-22$ & 109 & 0.823 & $0.627-1.078$ & 0.157 & \\
\hline $23-27$ & 74 & 0.763 & $0.565-1.029$ & 0.077 & \\
\hline$>27$ & 81 & 0.720 & $0.537-0.966$ & 0.028 & \\
\hline cigarettes per day (number) & 365 & & & & $<0.001$ \\
\hline $1-9$ & 49 & 1.000 & & & \\
\hline $10-14$ & 32 & 1.093 & $0.700-1.707$ & 0.694 & \\
\hline $15-19$ & 130 & 1.316 & $0.947-1.828$ & 0.101 & \\
\hline$\geq 20$ & 154 & 1.831 & $1.327-2.527$ & 0.001 & \\
\hline BMI $\left(\mathrm{kg} / \mathrm{m}^{2}\right)^{\Delta}$ & 491 & & & & \\
\hline$<18.5$ & 24 & 2.033 & $1.329-3.110$ & 0.001 & \\
\hline $18.5-23.9$ & 188 & 1.000 & & & \\
\hline $24-27.9$ & 221 & 1.030 & $0.847-|.25|$ & 0.769 & \\
\hline$\geq 28$ & 58 & 1.203 & $0.896-1.615$ & 0.219 & \\
\hline systolic blood pressure $(\mathrm{mmHg})$ & 491 & & & & $<0.001$ \\
\hline$<120$ & 95 & 1.000 & & & \\
\hline $120-129$ & 134 & 1.148 & $0.882-1.494$ & 0.306 & \\
\hline $130-139$ & 89 & 1.509 & $1.129-2.017$ & 0.005 & \\
\hline$\geq 140$ & 173 & 1.610 & $1.253-2.070$ & 0.001 & \\
\hline triglycerides (mg/dl) & 491 & & & & $<0.001$ \\
\hline$<90$ & 101 & 1.000 & & & \\
\hline $90-122$ & 117 & $1.25 \mid$ & $0.958-1.634$ & 0.100 & \\
\hline$|23-15|$ & 142 & 1.647 & $1.275-2.128$ & 0.001 & \\
\hline$\geq 152$ & 131 & 1.435 & $1.106-1.862$ & 0.007 & \\
\hline
\end{tabular}

*Adjusted for age, systolic blood pressure, BMI, total cholesterol, triglycerides, regular alcohol consumption, Exercise, as well as existing disease at baseline; $\triangle \mathrm{BMI}$ was grouped by Chinese standard.

ischemic stroke and type 2 diabetes mellitus increase steadily with increasing BMI. Raised BMI also increases the risks of cancer of the breast, colon, prostate, endometrium, kidney and gallbladder. In 2000 there were more than one billion adults worldwide overweight and at least 300 million clinically obese $[8,9]$. Obesity rates had raised three-fold or more since 1980 in some areas of
North America, the United Kingdom, Eastern Europe, the Middle East, the Pacific Islands, Australasia and China. A new demographic transition in developing countries is producing rapid increases in BMI, particularly among the young. In China, another study got the similar result, i.e. underweight were associated with an increased risk of 
death in middle-aged men who had never smoked cigarettes [10].

Our result showed that risk of death raised by $0.9 \%$ while systolic blood pressure raised by $1 \mathrm{mmHg}$. When adjusted for systolic blood pressure by dividing this continuous variable into 4 categories, death risks increased significantly with increased age $(\mathrm{P}<0.05)$. Porgeirsson [11] also found that age, serum total cholesterol, triglycerides, smoking and systolic blood pressure were significant independent risk factors for CHD mortality in a prospective study of 8001 randomly selected Icelandic men and 8468 women. Menotti [12] found that age, systolic blood pressure, serum cholesterol and cigarette consumption were strongly and significantly associated with all-cause mortality, coronary mortality and cardiovascular mortality. With respect to triglyceride, risk of death raised by $0.2 \%$ while triglyceride raised by $1 \mathrm{mg} / \mathrm{dl}$. When the cohort was divided into four categories of triglyceride, death risks increased significantly with increased triglyceride $(\mathrm{P}<0.05)$. In China, He Yao [13] carried out a cohort study in a machinery factory in Xi'an, China and found that triglyceride was an independent risk factor. Eberly [14] and Johansson [15] reported the similar results.

Association between smoking and deaths was reported by Doll and Peto in 1976 [16]. Our result showed that smoking was an independent risk factor for death in the cohort. At baseline, smoking rate in the cohort were $69.40 \%$. Smoking rate was higher than those in the two census of the population in 1984 and 1996 (in which smoking rate of males were $61.01 \%$ and $66.94 \%$ respectively). When the subjects were divided into nonsmokers, former smokers and current smokers, current smokers' risk of all-cause death raised 0.369 when compared with nonsmokers. In current smokers, when divided into four categories according to smoking index in average, death risks increased significantly with increased smoking index $(\mathrm{P}<$ 0.05 , as figure 1 shows). Two variables were found to be important indicators for smoking, one was age of starting smoking, and the other was cigarettes per day. Death risk increased when age of starting smoking was younger. Compared with those whose age of starting smoking were higher than 27 years, death risk increased by $28 \%$ in those

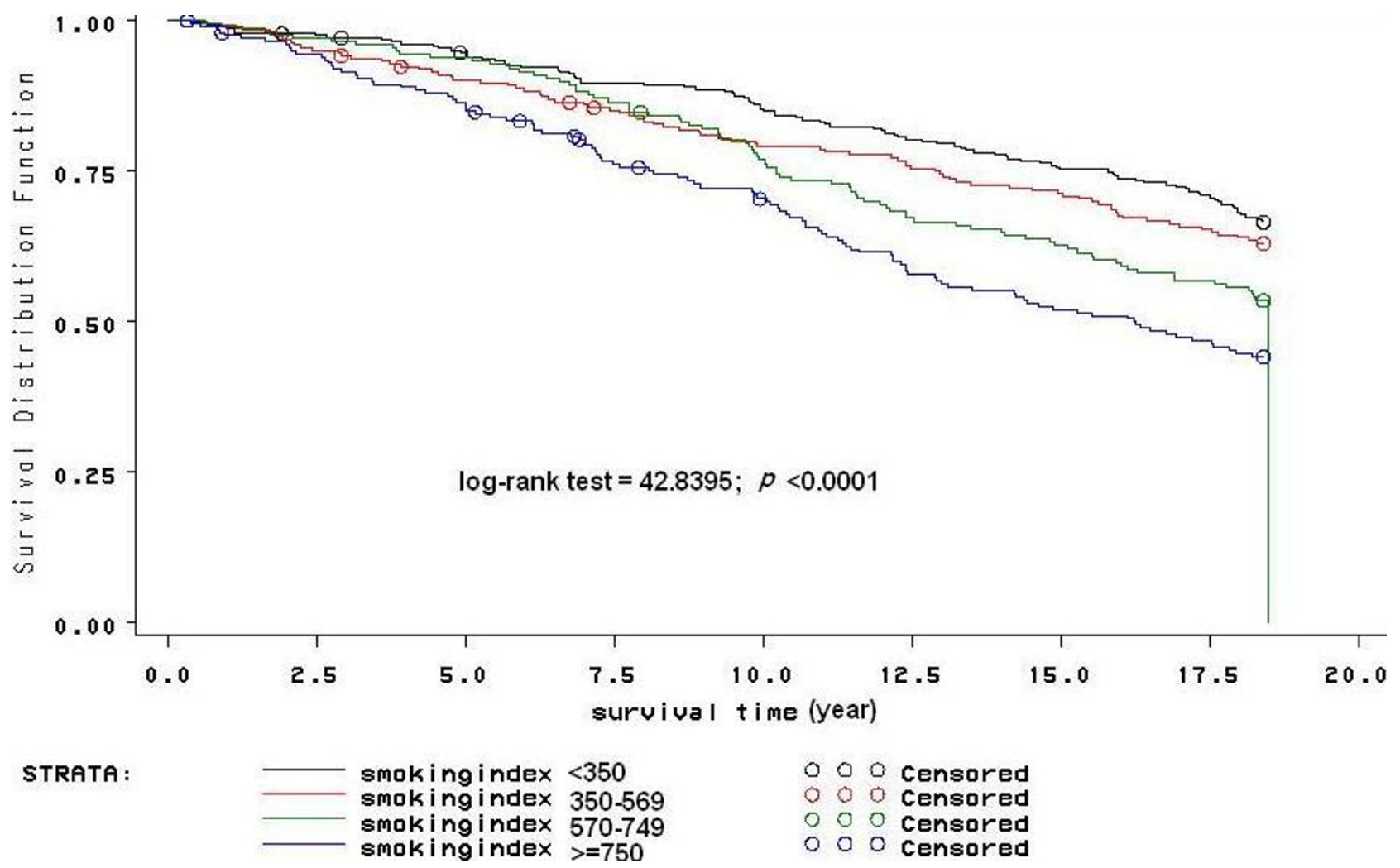

Figure I

Comparison of cumulative survival rate of different smoking index groups. Figure I shows a comparison of cumulative survival rate in different smoking index groups. Cumulative survival rate decreased with increasing smoking index. Although differences between groupl (smoking index $<350)$ and group2 $(350<$ smoking index $<569)$, group2 and group3 (569<smoking index $<749)$ were not significant, there were significant differences between the other two groups $(P<0.05)$. 
whose age of starting smoking were lower than 19 years. Death risks also increased significantly with increased cigarettes per day $(\mathrm{P}<0.05)$. Our results are similar to many prospective studies about smoking and related diseases in the world, finding smoking an independent risk factor for all-cause death [17-24].

As Yang reported previously [25], smoking accounted for one million deaths in China in 2000, which was $12 \%$ of total deaths. If no actions were taken, the proportion would rise to $33 \%$, of death attributable to smoking corresponding to two million smoking-related deaths. Smoking rate of adolescents in China has risen dramatically in recent years. Age of start smoking in 2002 was four to five years earlier than that in 1984. Passive smoking is becoming more serious. As $60 \%$ of the Chinese population is passive smokers, it is urgent to develop public health measures to control the smoking problem.

According to WHO, three major risk factors for chronic disease are: unbalanced diet, physical inactivity and smoking. High blood pressure, high cholesterol, obesity, overweight, and low fruit and vegetable intake are dietrelated risk factors. It is vital to control chronic disease risk factors in the population. If mortality of chronic diseases could reduce by $2 \%$ every year, 36 million lives would be saved in the following 10 years. And it will bring economic returns to the world, especially the developing countries.

There are limitations in our study. Results were based on a retired male military cohort and the representation to the general population is limited. The follow up time was short and numbers of death were small. As a result, some risk factors of all-cause mortality could not be analyzed in this cohort, e.g. drinking and diastolic blood pressure. Younger smokers could have died from smoking before retirement, and therefore were not detected in this retired cohort.

\section{Conclusion}

The three leading causes of death were cancer, CHD and stroke disease and COPD.

Aging, cigarette smoking, high systolic blood pressure, high triglyceride, family history of hypertension, stroke and cancer, existing cases recovering from stroke, diabetes and malignant tumor, underweight, younger age of smoking were risk factors for all-cause mortality. Quitting smoking, keeping suitable levels of blood pressure, triglyceride and weight will benefit us undoubtedly.

Smoking is a major cause of death in Chinese retired military veterans. Prompt quitting of cigarette smoking should be emphasized in the control of the growing epidemic of tobacco-related diseases.

\section{Abbreviations}

BMI: body mass index

COPD: chronic obstructive pulmonary disease

HR: hazard ratio

CI: confidence interval

CHD: coronary heart disease

\section{Competing interests}

The author(s) declare that they have no competing interests.

\section{Authors' contributions}

XYS contributed to the design of the present analysis of the study, the acquisition of data, carried out the data analysis, interpreted the data and drafted the manuscript.

YH contributed to the conception and design of the study and revised the manuscript for important intellectual content.

MK contributed to the acquisition of data.

BW contributed to the acquisition of data.

JYH contributed to the acquisition of data.

QLS contributed to the acquisition of data.

LZ contributed to the acquisition of data.

LSL contributed to revise the manuscript for important intellectual content.

CBCK contributed to revise the manuscript.

YPY contributed to the conception and design of the study, the acquisition of data, and revised the manuscript for important intellectual content.

All authors have read and approved the final manuscript.

\section{Acknowledgements}

The authors wish to thank the doctors of 323 Hospital, 45I Hospital, the staff of 22 Retirement Centers and 12 undergraduates of FMMU for their careful collection of the data and making the surveys possible.

\section{References}

I. Preventing chronic diseases: a vital investment [http:// www.who.int/chp/chronic disease report/partl/zh/indexl.html] 
2. WHO/MONICA-Project: Multinational Monitoring of Trends and Determinants in Cardiovascular Diseases (MONICA Project) and Manual of Operation. Geneva, Switzerland: World Health Organization, Cardiovascular Disease Unit; 1983.

3. Lam TH, He Y, SHI QL, Huang JY, Zhang F, Wan ZH, Sun CS, Li LS: Smoking, Quitting and Mortality in a Chinese Cohort of Retired Men. Ann Epidemiol 2002, I 2(5):316-320.

4. Chinese Health service statistics report in 2005 [http://
] www.moh.gov.cn/open/uploadfile/200642584823II0.doc]

5. Eaker ED, Sullivan LM, Kelly-Hayes M, D'Agostino RB Sr, Benjamin EJ: Does job strain increase the risk for coronary heart disease or death in men and women? The Framingham Offspring Study. Am J Epidemiol 2004, 159( 10 ):950-958.

6. Flegal KM, Graubard BI, Williamson DF, Gail MH: Excess deaths associated with underweight, overweight, and obesity. JAMA 2005, 293(I5): |86|-| 867.

7. Willett WC, Hu FB, Colditz GA, Manson JE: Underweight, Overweight, Obesity, and Excess Deaths. JAMA 2005, 294(5):55I.

8. Cooperative Meta-analysis Group of China Obesity Task Force: Predictive values of body mass index and waist circumference to risk factors of related diseases in Chinese adult population. Chin J Epidemiol 2002, 23(I):5-10.

9. World Health Organization: Obesity: preventing and managing the global epidemic. WHO Technical Report. Geneva 2000.

10. Yuan JM, Ross RK, Gao YT, Yu MC: Body weight and mortality : a prospective evaluation in a cohort of middle-aged men in Shanghai, China. Int J Epidemiol I998, 27(5):824-832.

II. Porgeirsson G, Davidsson D, Sigvaldason H, Sigfusson N: Coronary risk factors among men and women in Iceland. Results from the Reykjavik Study 1967-1985. Laeknabladid 2005, 91(I): I07-II4.

12. Menotti A, Kromhout D, Blackburn H, Jacobs D, Lanti M: Forty-year mortality from cardiovascular diseases and all causes of death in the US Railroad cohort of the Seven Countries Study. Eur J Epidemiol 2004, 19(5):4I7-424.

13. He Y, Lam TH, Li LS, Li LS, He SF, Liang BQ: Triglyceride and coronary heart disease mortality in a 24-year follow-up study in Xi'an, China. Ann-Epidemiol 2004, I4(I): I-7.

14. Eberly LE, Stamler J, Neaton JD: Relation of triglyceride levels, fasting and nonfasting, to fatal and nonfatal coronary heart disease. Arch Intern Med 2003, 163(9): 1077-1083.

15. Johansson S, Wilhelmsen L, Lappas G, Rosengren: A High lipid levels and coronary disease in women in Goteborg-outcome and secular trends: a prospective 19 year follow-up in the BEDA*study. Eur Heart / 2003, 24(8):704-7/6.

16. Doll R, Peto R: Mortality in relation to smoking: 20 years' observations on male British doctors. BM] [976, 2(605 I): $|525-| 536$

17. Chen ZM, Xu Z, Collins R, Li WX, Peto R: Early health effects of the emerging tobacco epidemic in China. A 16 -year prospective study. JAMA 1997, 278( I 8): I 500-1504.

18. Yuan JM, Ross RK, Wang XL, Gao YT, Henderson BE, Yu MC: Morbidity and Mortality in Relation to Cigarette Smoking in Shanghai, China: a prospective male cohort study. JAMA 1996, 275(2I): 1646-1650.

19. Liu BQ, Peto R, Chen ZM, Boreham J, Wu YP, Li JY, Campbell TC Chen JS: Emerging tobacco hazards in China. I. Retrospective proportional mortality study of one million deaths. BMJ 1998 , 3 I 7(7 |70): |4||-|422.

20. Niu SR, Yang GH, Chen ZM, Wang JL, Wang GH, He XZ, Schoepff $H$, Boreham J. Pan HC, Peto R: Emerging tobacco hazards in China.2.Early mortality results form a prospective study. $B M J$ 1998, 317(7170): I423-I424.

21. Lam TH, He Y, Li LS, Li LS, He SF, Li BQ: Mortality attributable to cigarette smoking in China. JAMA 1997, 278(18): I505- I508.

22. Peto R: Smoking and death: the past $\mathbf{4 0}$ years and the next 40 . $B M]$ I 994, 309(6959):937-939.

23. Peto R, Chen ZM, Boreham J: Tobacco the growing epidemic in China. JAMA 1996, 275(21):1683-1684.

24. Gupta PC, Mehta HC: Cohort study of all-cause mortality among tobacco users in Mumbai, India. Bulletin of the World Health Organization 2000, 78(7):877-883.

25. Yang GH, Ma JM, Liu N, ZHOU LN: Smoking and passive smoking in Chinese, 2002. Chin J Epidemiol 2005, 26(2):77-83.

\section{Pre-publication history}

The pre-publication history for this paper can be accessed here:

http://www.biomedcentral.com/1471-2458/7/290/pre pub
Publish with Biomed Central and every scientist can read your work free of charge

"BioMed Central will be the most significant development for disseminating the results of biomedical research in our lifetime. "

Sir Paul Nurse, Cancer Research UK

Your research papers will be:

- available free of charge to the entire biomedical community

- peer reviewed and published immediately upon acceptance

- cited in PubMed and archived on PubMed Central

- yours - you keep the copyright
BioMedcentral 